\title{
O ESTRESSE E OS IMPACTOS NO AMBIENTE HOSPITALAR E NA SAÚDE DO TRABALHADOR NO HOSPITAL DE COARI NO MÉDIO RIO SOLIMÕES
}

\author{
Edevanilson da Silva Dantas ${ }^{1}$
}

\section{Ademar Vieira dos Santos ${ }^{2}$}

RESUMO: As atividades laborais no campo da saúde têm sido apontadas como tendo um dos mais altos índices favoráveis para desenvolver o fenômeno do estresse e, neste ranque, a enfermagem aparece como a profissão mais estressante. Fato que nos remete a refletir quanto aos riscos ocupacionais que circunda o enfermeiro e considerar o grau de responsabilidade pela vida do paciente por estar no ambiente hospitalar em contato direto com situações de sofrimento, morte e outras questões que afetam a emoção deste profissional. Trata-se de uma investigação exploratória para compreender o estresse em diferentes ocupações do enfermeiro. O estudo foi constituído pela população de 18 enfermeiros que estão inseridos no serviço Público de Saúde de Coari que trabalham no hospital. Todos participaram da pesquisa respondendo a um questionário individual semi-estruturado. Para análises dos dados foi realizada categorização e, como resultado, observou-se que os sinais e sintomas mais frequentes percebidos são dor, irritação e isolamento. Constatou-se também que a falta de material hospitalar causa bastante tensão no ambiente de trabalho dos enfermeiros. Foi possível constatar que as melhores estratégias de enfrentamento do estresse no ambiente hospitalar consistem em dormir e praticar atividades físicas. O termo estresse significa esforço de adaptação do organismo para enfrentar situações que considere ameaçadoras à sua vida e ao seu equilíbrio interno. Contudo, é necessário aprender com os sintomas, de modo que estes possam ser

\footnotetext{
${ }^{1}$ Orientando: Formado em Enfermagem pela Universidade Federal do Amazonas/ISB/CoariAM

2 Orientador: Formado em Pedagogia, Mestre em Educação Ambiental e Professor da Universidade Federal do Amazonas.
} 
superados, para que o indivíduo, através do conhecimento pessoal, crie condições de modificar seu contexto ou aprender a conviver com o mesmo, sem perder o equilíbrio do organismo.

Palavras chaves: Estresse ocupacional. Ambiente.

\section{INTRODUÇÃO}

Atualmente as atividades laborais voltadas para as ciências da saúde, como a profissão de enfermagem, têm sido apontadas como uma das mais estressantes, se comparadas a outras áreas de trabalho, uma vez que a intensidade da vivência que o enfermeiro experimenta no seu cotidiano Ihe exige uma contínua e profunda mobilização de energia adaptativa que, por vários motivos, pode não estar disponível ou pode não ser suficiente para evitar o estresse. Os riscos para a saúde relacionados com o trabalho dependem da complexidade do tipo de atividade profissional e das condições ambientais em que é desempenhada. "O ambiente é formado por constituintes heterogêneos inseparavelmente associados; o mundo fenomênico está constituído por um tecido de ações, interações, retroações, determinações e eventualidades" (LUZZI 2003, p.187)

Muitos trabalhadores de diferentes classes funcionais estão sujeitos a esta síndrome inclusive os profissionais da equipe de enfermagem, devido, sobretudo, aos fatores intrínsecos ao trabalho, às relações funcionais, ao papel desempenhado pela equipe, estrutura organizacional, o grau de responsabilidade pela vida do cliente e, talvez por estar em contato direto com situações de sofrimento, morte e outras questões que vão afetar intrinsecamente a emoção deste profissional de enfermagem, caracterizando quanto à sua natureza uma susceptibilidade ao fenômeno do estresse.

O termo estresse foi introduzido por Selye, em 1930, nos campos da psicologia e da medicina. Ele definiu estresse como a reação do organismo a uma situação ameaçadora ou depressiva. Ele distinguiu entre o "estressor", como a causa externa, e "estresse", como a reação do corpo humano, (...) A confusão no uso dos termos contribuiu para o comentário popular confuso de "sentir-se estressado" (KROMER et al, 2005).

Então, partindo desta afirmação, conceituar estresse torna-se difícil, podendo ser elucidado separadamente na abordagem onde mostra a existência de três formas de 
definição: como estímulo, como resposta ou como interação ou transação entre ambiente interno e externo do Indivíduo. Admitem-se estas três questões envolvidas na conceituação segundo distintas abordagens: (1) como estímulo, com o enfoque no impacto dos estressores; (2) como resposta, quando examina a tensão produzida pelos estressores; e (3) como processo, quando entendido a partir da interação entre pessoa e ambiente (STACCIARINI et al, 2001).

O estresse ocupacional é uma consequência da exposição a fatores de riscos de natureza psicossocial relacionados com a organização do trabalho (SANTOS, 2005).

A modificação do ambiente funcional tem seguido os avanços das tecnologias de uma maneira mais veloz do que a capacidade de adaptação dos trabalhadores. A tensão é percebida continuamente nos profissionais não só no local de trabalho mas, sobretudo, na vida em geral.

Então, há uma relevância na compreensão quanto à definição de estresse no trabalho, pois, a partir das respostas aos eventos estressores, pode-se apontar sua contribuição para a identificação e compreensão de consequências do estresse e a devastação psicológica que o estresse pode causar.

Partindo deste pressuposto, surgiu o interesse em investigar as possíveis causas e fatores, componentes estressores nos profissionais de enfermagem em Coari, para que pudesse haver uma maior compreensão comparando o ambiente e a realidade local com as literaturas existentes e trabalhos realizados em outros hospitais.

Diante do compromisso de desvelar a problemática em questão foram elaborados os seguintes objetivos:

Geral: verificar o estresse ocupacional no profissional enfermeiro que trabalha no hospital regional de Coari-Am e o meio ambiente hospitalar.

Objetivos específicos:

- Reconhecer os sinais e sintomas do estresse no profissional enfermeiro da equipe de enfermagem no ambiente hospitalar.

- Identificar os elementos estressores em diferentes atividades ocupacionais dos profissionais enfermeiros no ambiente de trabalho.

- Investigar quais as estratégias e técnicas de enfrentamento ao estresse utilizadas pelos profissionais enfermeiros no ambiente do Hospital Regional de Coari. 


\section{CONCEITUANDO ESTRESSE}

De acordo com Lipp, (2001), o estresse é uma reação do organismo, com componentes físicos e/ou psicológicos que ocorre quando a pessoa se confronta no ambiente onde ela vive com situação que irrite, amedronte ou a faça imensamente feliz.

Existe uma analogia de compreensão de concordância entre os autores em conceituar estresse, mas este termo estresse nos dias atuais tem um significado que demonstra similaridades com as literaturas, como sendo o estresse a maneira como o organismo responde a qualquer estímulo bom, ruim, mal ou imaginário que altere seu estado de equilíbrio.

\subsection{REAÇÃO FISIOLÓGICA AO ESTRESSE}

O processo de estresse tem início com os receptores, que espalhados por todo o corpo captam as alterações no ambiente. Os sinais captados chegam até o tálamo cerebral, que repassa a mensagem ao hipotálamo. Este libera uma substância chamada de Fator Liberador de Corticotrofina (CRF), que estimula a glândula hipófise a liberar Hormônio Adenocorticóide - (ACTH) (FIAMONCINI et al., 2003).

O principal destino do ACTH são as glândulas supra-renais que passam a distribuir diferentes substâncias químicas para diferentes destinos, como a adrenalina, os mineralocorticóides e os glicocorticóides, todos com o objetivo de estimular o organismo para "luta ou fuga", desencadeando ,assim, os sintomas referentes ao estresse. Aumento dos batimentos cardíacos e, consequentemente,elevação momentânea da pressão arterial são as manifestações básicas do estresse agudo, ativado pela ação da adrenalina e noradrenalina via Sistema Nervoso Simpático. Já no estresse crônico a pressão arterial se mantém elevada, tornando a pessoa hipertensa, e as consequências desse estado podem ser derrame cerebral, ruptura de aneurismas ou mesmo parada cardíaca. Este efeito hipertensivo do stress crônico é mediado pela liberação continuada de cortisol pelo córtex supra-renal. 
Em uma primeira fase, nossos músculos se contraem, o coração e os pulmões aumentam o ritmo de funcionamento, o estômago para a digestão dos alimentos, a pressão arterial sobe, a circulação do sangue é desviada predominantemente para os músculos e o cérebro, e mais substratos (glicose e ácidos graxos) são colocados na circulação para produzir energia para a contração muscular. Essa primeira fase depende essencialmente da ação da adrenalina e é referida como a preparação para luta ou fuga.

Depois de 10 minutos, e persistindo a situação de estresse, o organismo entra numa segunda fase, onde são liberados os hormônios glucocorticóides (cortisona, cortisol e corticosterona).

O stress, ao contrário da crença popular, não é meramente fadiga nervosa ou consequência de intensa emoção. Qualquer atividade normal - um jogo de xadrez ou um abraço carinhoso - pode produzir considerável stress sem maiores consequências. Assim, o estímulo pode ter origem agradável ou desagradável, agudo ou crônico, mas a reação do organismo segue um mesmo padrão.

A reação fisiológica é acompanhada de sintomas psíquicos e comportamentais, que tomam formas diferentes, de acordo com cada indivíduo (FIAMONCINI et al., 2003).

Quando nos deparamos com uma situação de stress, nossas reações seguem um padrão descrito por Lipp e Novaes (2001), chamado de Síndrome Geral de Adaptação, que, consiste em três fases:

1. Reação de Alarme;

2. Reação de Resistência;

3. Reação de Exaustão.

Os níveis de tolerância ao estresse são diferentes para cada indivíduo. Pessoas com limites mais elásticos possuem maior resistência a ele. Porém, ao serem submetidos à tensão constante e crescente, igualmente como qualquer elástico, irá se romper, o que significa que corpo e mente adoece. Quanto melhor for a reação de um indivíduo ao estresse, menos sintomas físicos relacionados a ele ocorrerão.

\subsection{AS CARACTERÍSTICAS DE UM SER HUMANO ESTRESSADO}


Caracterizar um ser humano estressado está ligado intrinsecamente aos sinais e sintomas que este apresenta diante de fatores ou situações desagradáveis que desencadeiam um desconforto, levando sempre em consideração as sobrecargas diárias e o acúmulo de tensões sobrepostas neste indivíduo.

Fernandes et al (2008), demonstra que o estresse ocorre devido à sobrecarga de trabalho: algo que exige em excesso do trabalhador e que leva à sensação de estar no limite de uma somatória de situações estressantes, tendo como desdobramentos o cansaço e a falta de paciência.

Já Bermúdez apud Lautert (1999) afirma que uma das características individuais que interfere na percepção do ambiente é o grau de ansiedade do indivíduo. A ansiedade pode causar bloqueios de memória e os indivíduos mais ansiosos tendem a render menos em tarefas onde são avaliadas a retenção de materiais previamente aprendidos.

Lipp (2001), afirma que o processo de estresse ocorre em três fases.

O indivíduo depara-se com um (a) estímulo (condição) estressor (a), como por exemplo: nova paixão; emprego novo tão desejado; aprovação; promoção; beijo; falta de tempo para lazer; trânsito caótico; contas a pagar; salário congelado; intensa competição; ameaça de um predador; mudança súbita, brusca e ameaçadora na posição social e/ou nas relações do indivíduo; ameaça à segurança ou integridade física e emocional da própria pessoa ou de pessoa por ela amada; vida afetiva em desequilíbrio; conflito prolongado; guerra; acidente; assalto; sequestro; estupro; catástrofe natural; injeções de proteínas estranhas ao organismo; frio intenso; anestesia, cirurgia. Diante de um (a) ou mais dos (as) estímulos (condições) citados (as), o indivíduo entra na $1^{\underline{a}}$ Fase descrita denominada fase de Alarme. Nesta fase o organismo entra em estado de alerta para se proteger do perigo percebido e dá prioridade aos órgãos de defesa, ataque ou fuga.

As reações corporais desenvolvidas nesta fase são: dilatação das pupilas; estimulação do coração (palpitação), a noradrenalina, produzida nas glândulas suprarenais acelera os batimentos cardíacos e provoca uma alta de pressão arterial, o que permite uma melhor circulação do oxigênio; a respiração se altera (tornando-se ofegante) e os brônquios se dilatam para poderem receber maior quantidade de oxigênio; aumento na possibilidade de coagulação do sangue (para assim poder fechar possíveis ferimentos); o fígado libera o açúcar armazenado para que este seja usado pelos 
músculos; redistribuição da reserva sanguínea da pele e das vísceras para os músculos e cérebro; frieza nas mãos e pés; tensão nos músculos; inibição da digestão (inibição da produção de fluidos digestivos, inibição dos movimentos peristálticos do percurso gastrointestinal); inibição da produção de saliva (boca seca).

Caso o indivíduo consiga lidar com o estímulo estressor, eliminando-o ou aprendendo a lidar com o mesmo, o organismo volta à sua situação básica de equilíbrio interno (homeostase) e continua sua vida normal. Mas, se ao contrário, o estímulo persistir sendo entendido como estressor e, caso o indivíduo não tenha encontrado uma forma de se reequilibrar, vai ocorrer uma evolução para as outras duas fases do processo de estresse.

Na $2^{\text {a }}$ Fase, denominada fase de Resistência, Intermediária ou "Estresse" contínuo, persiste o desgaste necessário à manutenção do estado de alerta. $\mathrm{O}$ organismo continua sendo provido com fontes de energia rapidamente mobilizadas, aumentando a potencialidade para outras ações no caso de novos perigos imediatos serem acrescentados ao seu quadro de "Estresse" contínuo. O organismo continua a buscar ajustar-se à situação em que se encontra.

Toda essa mobilização de energia traz algumas consequências como: redução da resistência do organismo em relação a infecções; sensação de desgaste, provocando cansaço e lapsos de memória; supressão de várias funções corporais relacionadas com o comportamento sexual, reprodutor e com o crescimento. Exemplos: queda na produção de espermatozóides; redução de testosterona; atraso ou supressão total da puberdade; diminuição do apetite sexual; impotência; desequilíbrio ou supressão do ciclo menstrual; falha na ovulação ou falha no óvulo fertilizado ao dirigir-se para o útero; aumento do número de abortos espontâneos; dificuldades na amamentação (TOWNSEND, 2002).

Com a persistência de estímulos estressores, o indivíduo entra na $3^{\underline{a}}$ Fase, denominada fase de Exaustão ou esgotamento, onde há uma queda na imunidade e o surgimento da maioria das doenças, como por exemplo: dores vagas; taquicardia; alergias; psoríase; caspa e seborréia; hipertensão; diabete; herpes; graves infecções; problemas respiratórios (asma, rinite, tuberculose pulmonar); intoxicações; distúrbios gastrointestinais (úlcera, gastrite, diarréia, náuseas); alteração de peso; depressão; ansiedade; fobias; hiperatividade; hipervigilância; alterações no sono (insônia, pesadelos, 
sono em excesso); sintomas cognitivos como dificuldade de aprendizagem, lapsos de memória, dificuldade de concentração; bruxismo o que pode ocasionar a perda de dentes; envelhecimento; distúrbios no comportamento sexual e reprodutivo;

\subsection{FATORES NO AMBIENTE DE TRABALHO QUE DESENCADEIAM} ESTRESSE NA EQUIPE DE ENFERMAGEM.

Nota-se que o estilo de vida frenético dos trabalhadores de enfermagem decorre, muitas vezes, de necessidades financeiras e manutenção de um padrão social. Isto conduz esse profissional a estabelecer para si um ritmo rigoroso de atividades que podem envolver os vínculos empregatícios e a vida doméstica podendo, desta forma, propiciar o estresse.

Soma-se a isso, a realidade imposta pela profissão como o fato de trabalhar em situações adversas que impõe grande demanda de atividades variadas em turnos diferentes, podendo afetar o desempenho físico, mental e emocional.

Geralmente o profissional de enfermagem possui mais de um vínculo empregatício. Deve ser considerado um tempo destinado ao lazer e, como a maioria dos trabalhadores pertence ao gênero feminino, a jornada de trabalho doméstico também deve ser considerada na análise da qualidade de vida desses profissionais (SILVA e MELO, 2006).

Os baixos salários obrigam os profissionais a possuir mais de um emprego, o que resulta em uma carga mensal muita longa e desgastante, caracterizando a sobrecarga de trabalho (MUROFUSE; ABRANCHES, NAPOLEÃO, 2005).

Para Batista e Bianchi (2006): A carga de trabalho é o estressor mais proeminente na atividade do enfermeiro, além dos conflitos internos entre a equipe e a falta de respaldo do profissional, sendo a indefinição do papel profissional um fator somatório aos estressores. (BATISTA; BIANCHI, 200, p.535).

$\mathrm{O}$ trabalho pode alterar a saúde mental das pessoas nos aspectos relacionados à organização do trabalho, com a divisão e o parcelamento das tarefas, as políticas de gerenciamento de pessoas e a estrutura hierárquica organizacional (BRASIL, 2001).

Segundo Murofuse, Abranches e Napoleão (2005), as atividades do enfermeiro são muitas vezes estafantes e em locais inadequados. Mesmo assim, não recebem a 
proteção e atenção necessária para evitar doenças e acidentes decorrentes das atividades.

Em sua formação, os enfermeiros não obtêm meios para lidar com os aspectos emocionais e psicológicos necessários ao atendimento de pessoas em situação de morte, bem como atender familiares. A dificuldade em abordar o assunto faz com que o enfermeiro evite permanecer próximo aos familiares (FISCHER e SILVA, 2003).

O contato intenso com os pacientes e seus familiares pode ser acompanhado por sentimentos de tensão, ansiedade e hostilidade encoberta. Essas situações podem gerar sensação de ineficácia profissional e insatisfação no ambiente de trabalho (ROSA e CARLOTTO, 2005).

Segundo Martinas (2000), o estresse pode desencadear muitas patologias físicas e mentais, implicando em sérias alterações no ambiente de trabalho como problemas de relacionamento interpessoal, absenteísmo, acidentes e insatisfação no trabalho.

De acordo com Bianchi (2000), os fatores externos como o trabalho, a família e o ambiente influenciam na percepção do estresse, assim como os fatores internos como as emoções, experiências anteriores, crenças e valores.

Ambientes que não possibilitam a comunicação espontânea, a manifestação de insatisfações, as sugestões com relação à organização e ao trabalho podem provocar sofrimento e distúrbios mentais. Além disso, ocorrerão altos índices de absenteísmo e conflitos dentro e fora do trabalho (BRASIL, 2001).

Quando o trabalho é realizado em condições insalubres e inseguras, como o contato com riscos químicos, físicos e biológicos, pode afetar o bem-estar físico e psíquico do indivíduo. Sendo assim, a estrutura organizacional da instituição hospitalar tem que ser provida de instrumentos de trabalho, de acordo com as normas de biossegurança (BATISTA; BIANCHI, 2006).

A desvalorização do profissional da saúde, a precarização das relações de trabalho, o baixo investimento em educação permanente destes trabalhadores, a pequena participação na gestão dos serviços e o frágil vínculo com os usuários são exemplos da falta de humanização nas organizações. Além disso, os modelos de gestão centralizados e verticais desapropriam o trabalhador de seu próprio processo de trabalho (BRASIL, 2004). 
De acordo com Murofuse, Abranches e Napoleão (2005), o tipo de organização pode impossibilitar o vínculo afetivo nas atividades do cuidado, devido às regras a serem cumpridas. Com isso, pode instalar-se uma situação de tensão no indivíduo, pois fica difícil liberar essa energia afetiva.

Segundo Stacciarini e Troccoli (2001), a profissão do enfermeiro tem uma característica intrínseca que se denomina indefinição do papel profissional, o que pode ser mais um estressor, pois se sente desmotivado por ter que assumir funções que não deveriam ser de sua competência. Além disso, a enfermagem é uma das profissões mais estressantes, pois trabalha com enfermidades críticas e com situações de morte.

Segundo Santos, Oliveira e Moreira (2006), ao lidarem com diferentes categorias profissionais, os enfermeiros se veem algumas vezes em situações conflitantes, pois os diferentes profissionais possuem interesses e visões de mundo diferentes, o que pode propiciar situações tensas no ambiente de trabalho.

O autor argumenta que os estressores ocupacionais têm recebido atenção especial pelos pesquisadores e o fenômeno tem sido definido como tensões e problemas advindos do exercício de uma atividade ocupacional. O trabalho do enfermeiro, por sua própria natureza e características, revela-se especialmente suscetível ao fenômeno do estresse ocupacional.

\subsection{ESTRATÉGIAS E TÉCNICAS PARA O ENFRENTAMENTO DO AMBIENTE DE ESTRESSE}

Identificar e conhecer as causas que levaram ao estresse é fundamental para que o profissional possa desenvolver estratégias de enfrentamento do problema. Reconhecer a participação do trabalhador dentro do processo de trabalho e fazê-lo sentir parte deste favorece a motivação e proporcionam melhor qualidade de vida, tanto para o profissional quanto da sua assistência prestada. (NETO et al., 2008).

A Política Nacional de Humanização (PNH) do Ministério da Saúde define que é necessário haver melhores condições para que os profissionais executem seu trabalho de modo digno e criador de novas ações, e que possam atuar como co-gestores de seu processo de trabalho. Além disso, deve haver o fortalecimento do trabalho 
multiprofissional, estimulando a transdisciplinaridade e a grupalidade. A gestão participativa garante o diálogo entre os profissionais, entre os profissionais e a população e entre os profissionais e a administração (BRASIL, 2004).

De acordo com (Mendes apud Magalhães et al., 2000), a organização pode realizar ações que favoreçam o bem estar dos trabalhadores como:

1. Proporcionar cuidados ao trabalhador, através da psicologia e psiquiatria;

2. Buscar a transformação das situações de trabalho potencialmente perigosas para a saúde mental e psicossocial;

3. Diminuir a exposição a esses riscos aos que já adoeceram, inserindo-os em outro setor;

4. Reestruturação interna das empresas, com o conhecimento sobre o papel dos coletivos de trabalho, a segurança e proteção à saúde no trabalho;

5. Orientação familiar, para evitar conflitos desgastantes para a saúde mental da família.

$\mathrm{Na}$ concepção de Townsend, (2002), como estratégias de ajustes ou controle do estresse é necessário fazer uma avaliação de consciência e reconhecer quais fatores estão desencadeando o estresse.

Práticas de relaxamento, meditação, comunicação interpessoal com familiares e amigos,ouvir músicas com finalidade de estimular a motivação e o prazer são algumas destas tentativas de controle do estresse.

\section{METODOLOGIA}

Trata-se de uma pesquisa de campo de caráter descritiva exploratória, com abordagem quali-quantitativa realizada com base em experiências vivenciadas pelos enfermeiros em diferentes ocupações exercidas no Hospital Regional de Coari-AM.

De acordo com Severino (2007), através da pesquisa exploratória se faz os levantamentos de informações sobre um objeto, para delimitar o campo de trabalho, ou seja, há uma preparação para a pesquisa descritiva ou explicativa, caracterizada por registrar e analisar os fenômenos estudados, procurando sua identificação de causa, através de método experimental. 
O estudo foi realizado com 18 enfermeiros que trabalham no Hospital Regional de Coari que foram entrevistados sobre o estresse ocupacional.

Os enfermeiros do referido Hospital receberam a visita do pesquisador para marcar um encontro, sendo combinado verbalmente o horário da entrevista.

Para a realização das entrevistas, os profissionais foram informados sobre o estudo a ser realizado, enfocando seus objetivos, bem como o anonimato assegurado a cada um e outras questões éticas da pesquisa, deixando-lhes à vontade para que fizessem a opção de participarem ou não.

Após aceitar participar da pesquisa, o enfermeiro foi informado sobre a importância do seu consentimento por escrito, autorizando sua participação de forma voluntária na pesquisa, Ihe garantido a confidencialidade, sigilo e privacidade. Assim, os enfermeiros que concordaram em participar do estudo, assinaram o termo de consentimento Livre e Esclarecido.

A população do estudo inicialmente foi de 24 enfermeiros, número total de funcionários nesta categoria no Hospital escolhido para estudo. Portanto, apenas 18 se enquadraram nos critérios de Inclusão e 6 enfermeiros se enquadraram nos critérios de exclusão.

Esta pesquisa passou pela aprovação do Comitê de Ética e Pesquisa CEP e, após aprovação, nos dirigimos ao campo de pesquisa a fim de coletar os dados.

Assim, este trabalho apresentou um público total de 18 enfermeiros que trabalham no Hospital Regional de Coari.

\section{CONCLUSÃo}

De acordo com os objetivos inicialmente construídos, com as contribuições esclarecedoras do quadro teórico, a metodologia, os dados coletados e analisados, podese observar que é impossível eliminar o estresse de nossas vidas: ele existe em todos os setores. Podemos, porém, evitar que se torne excessivo, através de algumas medidas 
que incluem mudanças em nossas atitudes perante os eventos corriqueiros e inesperados da vida, como prática de meditações, exercícios físicos e relaxamentos.

As exigências que o mercado de trabalho está impondo ao trabalhador estão em algumas situações, levando ao sofrimento psíquico. Alguns fatores foram identificados tais como: trabalhar em ambiente insalubre, a falta de recursos materiais e humanos, trabalhar com pessoas despreparadadas, falta de recursos financeiros e atraso na folha de pagamento, fazer turnos alternados, trabalhar em horário noturno, são considerados estressantes, influenciando o comportamento, tornando muitas vezes o trabalhador mais agressivo e impaciente.

Ligados a estes eventos observou-se a ansiedade, desmotivação com o trabalho, sobrecarga de tarefas, como óbice relevante, fazendo com que o rendimento do trabalhador seja insuficiente pelo fato deste não conseguir dar conta de cumprir suas tarefas que, na maioria das vezes, são repetitivas.

Portanto, não é possível ignorar o perigo de um estresse excessivo e prolongado para a própria vida. Porém, o conselho é não fugir, já que isto seria impossível, porém aprender a enfrentar o estresse de modo adequado.

\section{REFERÊNCIAS}

Ballone GJ, Moura EC-Estresse e Trabalho - in. PsiqWeb, Internet, disponível em www.psiqweb.med.br, revisto em 2008.

Batista KM, Bianchi ERF. Estresse do enfermeiro em unidade emergência. Rev Latinoam Enfermagem 2006 julho-agosto; 14(4):534-9 www.eerp.usp.br/rlae. pesquisado em 30 de junho de 2010.

BIANCHI, Estela Regina Ferraz. (2000) Enfermeiro hospitalar e o stress. Rev. Esc. Enf. USP, v. 34, n. 4, p. 390394, dez. Disponível em < http://www.ee.usp.br/reeusp/upload/pdf/549.pdf> Acesso em: 03 de julho de 2000.

Fernandes SMBA, Medeiros SM, Ribeiro LM. Estresse ocupacional e o mundo do trabalho atual: repercussões na vida cotidiana das enfermeiras. Revista Eletrônica de Enfermagem [Internet]. 2008;10(2):414-427. Available from: http://www.fen.ufg.br/revista/v10/n2/v10n2a13.htm , pesquisado em 30 de junho de 2010. 
FILGUEIRAS, Julio Cesar; HIPPERT, Maria Isabel Steinherz. A Polêmica em Torno do Conceito de Estresse.Ed. Psicologia ciëncia e profissão. Recebido em 78/7 7/98 Aprovado em 2/10/99.

GIL, Antônio Carlos. Como elaborar projetos de pesquisa. $4^{\mathrm{a}}$ ed. São Paulo: Atlas, 2009.

GONÇALVES, Elisa Pereira. Conversa sobre a iniciação a pesquisa científica. 3 ed. Campinas, SP: Editora Alínea, 2003.

NAHAS, M. V. Atividade física, Saúde e Qualidade de Vida: Conceitos e Sugestões para um Estilo de Vida Ativo. Londrina: Midiograf, 2001.

KROMER, K.H.E e GRANDEJEAN. E. Manual de Ergonomia: adaptando o trabalho ao homem. 5 ed. Porto Alegre: Bookmam, 1987.

LUZZI, Daniel. A "ambientalização" da educação formal. Um diálogo aberto na complexidade do campo educativo. In: LEFF, Enrique. (coordenador) A complexidade ambiental. São Paulo: Editora Cortez 2003. 342 p.

LIPP, M.E.N. Estresse emocional: a contribuição de estressores internos e externos $\begin{array}{llllll}\text { Revista e Psiquiatria Clínica } 28 & (6): 347-349, & 2001 . & \text { Site: }\end{array}$ http://www.hcnet.usp.br/ipq/revista/index.html.

MINISTÉRIO DA SAÚDE. (2004) Humaniza SUS - Política Nacional de Humanização: A Humanização como Eixo Norteador das Práticas de Atenção e Gestão em todas as Instâncias do SUS, Brasília - DF. Disponível em < http://dtr2001.saude.gov.br/editora/produtos/impressos/folheto/04_0923_FL.pdf> Acesso em: 19 de janeiro de 2008.

MUROFUSE, Neide Liemi; ABRANCHES, Sueli Soldati; NAPOLEÃO, Anamaria Alves. (2005) Reflexões sobre estresse e Burnout e a relação com a enfermagem. Rev. Latinoam. Enfermagem, v. 13, n. 2, p. 255 - 261, Ribeirão Preto, mar./ apr. Disponível em < http://www.scielo.br/pdf/rlae/v13n2/v13n2a19.pdf> Acesso em: 30 de junho de 2010.

NETO, Nathanael Machado Coelho e GARBACCIO, Juliana Ladeira. 0 estresse ocupacional no serviço de enfermagem Hospitalar: reconhecimento e minimização. Interseção, Belo Horizonte, v. 1, n. 2, p. 71-81, abr. 2008.

SEVERINO, Antônio Joaquim: Metodologia do trabalho científico. 23 ed. Ver. E atualizada - São Paulo:Cortez, 2007. 
SILVA, J.L.L.; MELO, E.C.P. Estresse e implicações para o trabalhador de enfermagem. Disponível em:<http://www.uff.br/promocaodasaude/informe>. Acessado em: 10/04/2009.

STACCIARINI, Jeanne Marie R. e TROCCOLI, Bartholomeu T.. O estresse na atividade ocupacional do enfermeiro. Rev. Latino-Am. Enfermagem [online]. 2001, vol. 9, no. 2, pp. 17-25. ISSN 0104-1169.

TOWNSEND, Mary C. Enfermagem Psiquiátrica: Conceitos de cuidados. 3 ed. Rio de Janeiro: Editora Guanabara Koogan s.a, 2002. 